\title{
You're Fired: An Empirical Study of the Management and Termination Decisions in Donald Trump’s “The
}

\section{Apprentice”}

\author{
D. Anthony Miles \\ School of Business, Texas A\&M University-San Antonio \\ 1 University Way, San Antonio, Texas 78224
}

Tel: 210-362-0460 E-mail: dmiles@tamusa.tamus.edu or drderekx@yahoo.com

Received: August 172012 Accepted: September 14, 2012 Published: October 1, 2012

doi:10.5296/jmr.v4i4.2259ＵRL: http://dx.doi.org/10.5296/jmr.v4i4.2259

\begin{abstract}
Donald Trump's The Apprentice, is an entertaining and educational tool for teaching business and management principles. While, few studies have been conducted on The Apprentice, there have been no prior empirical studies assessing the program as a study for analyzing management decisions. This research attempts to fill that gap. The purpose of this study is to research management decision behavior on The Apprentice. This research was conducted on management students in undergraduate and graduate courses over a two-year period. A sample of $(N=173)$ participants were used for the study. The participants viewed various episodes of The Apprentice and then answered a questionnaire based on their observations and decisions. The data was collected following the observations and analyzed. The objectives of the analyses were to: (a) measure the participants' termination decisions; and (b) compare their termination decisions with Trump's boardroom termination decisions. Three statistical analyses were used: (a) independent sample $t$-Test, (b) ANOVA, and (c) Pearson correlation. The results indicated that management students agreed with Trump's termination decisions nearly $47.4 \%$ of the time.
\end{abstract}

Keywords: Management, firing, termination, decision-making, Donald Trump, The Apprentice 


\section{Introduction}

Since its inception in 2005, The Apprentice with Donald Trump has taken reality television viewers by storm. It has also taken business schools by storm. The realism of the show has provided some useful lessons for the classroom instruction. Many universities have used The Apprentice as a pedagogy tool. It has been used as a teaching tool for illustrating basic business principles and management theory.

The purpose of this study is to comparatively measure and evaluate management students' firing decisions with those of Trump's. Specifically, the study will identify whether age, gender, and ethnicity are determining factors in firing decisions when viewing episodes of The Apprentice. For the purposes of this study, a statistical research approach will be used to measure their decisions based on The Apprentice.

\section{Significance of the Study}

This research extends the previous studies on The Apprentice. This study is significant because it takes a different approach. This study takes an empirical approach to examining decisions on The Apprentice. The researcher wanted to measure management students' decision behavior and compare it to Trump's decisions on the television. This study will increase the body of knowledge providing an empirical examination of The Apprentice and management decision-making dynamics. The basis of the study will be to examine firing decisions as a framework to explore the impact of influences of gender and ethnicity. This is significant because it will add to the body of knowledge in management research. This study wanted to take a unique approach in examining the television show with management theory. This study is organized four sections: (a) background of the study; (b) literature review, which reviews the prior research and provides a basis for the study; (c) methodology and results; and (d) discussion and conclusions, will elaborate on the findings of the study.

\section{Literature Review}

Management theory continues to evolve and spout new disciplines of study as a behavioral science. Teaching management theory, in the classroom, has also evolved, as the sharing of knowledge is a never ending exchange of ideas and concepts. Donald Trump's The Apprentice, is an entertaining reality show on business and has been used as an educational tool. Many business programs, across the nation, have actually used The Apprentice, in undergraduate and graduate business programs. A central component of The Apprentice is management decision making. Based on the success or failure of the team, once they are in the boardroom, Trump makes a decision on who should be terminated. Trump's famous words, "You're fired" have resonated with millions of viewers.

The show follows a consistent scenario content and termination pattern. The first part of The Apprentice depicts the teams' struggles to complete the assigned task. Each team chooses a project leader, who is primarily accountable for the team's performance. Both teams are seen running around, clashing one another, and occasionally being professional and organized in their efforts. At times The Apprentice frequently disintegrates into reality show theatrics, 
replete with name-calling, backbiting, finger pointing, and lingering camera shots on the evicted loser's despondent face (Elliot, 2004).

\subsection{Prior Research on 'The Apprentice'}

Limited research has been conducted on The Apprentice. That is perplexing considering the show's popularity and its use in many university business programs, around the country. There is one known prior study conducted on The Apprentice. The basis of Kinnick and Parton's (2005) study was to determine the extent to which communication skills are presented as critical to success in contemporary American business in The Apprentice. The conclusions of their study were: (a) leadership skills and interpersonal skills were the most frequent subjects of criticisms, which far outnumbered comments of praise; (b) effective leadership and interpersonal skills are considered an essential "must have"; lack of them is a fatal flaw; and c) leadership skills were consistently identified most frequently as being critical to success, followed by interpersonal skills.

\subsection{Criticisms of 'The Apprentice'}

There have been many business principles and lessons to be learned from viewing The Apprentice. First, leaders can acquire power by mobilizing the collective energy, knowledge, and talents of team members (Popejoy, 2004). One observation centered on ethic decision-making. Terry Broderick, a former CEO, believes The Apprentice can have a very negative effect. She challenges the Trump's mantra, “just business and not personal." Furthermore she argued that you cannot have one set of values in your personal life and another set in your business life. That just does not work (Terry Broderick, interviewed by Henle, 2004).

One of the major criticisms of The Apprentice is that the made-for-TV scenarios do not always represent the reality of American business. Interestingly, the University of Washington developed a course based on The Apprentice (Gyenes, 2004; Ho, 2004; Kennick and Parton, 2005). Other observations view the media portrayal of business as a validation of preconceived notions. This view does not credit the vast majority of businesses in existence that work diligently to do the right thing by their employees, customers, and shareholders (Henle, 2004). Other criticisms have been lodged against business schools for using The Apprentice to teach business principles. The major criticism, by Gyenes (2004), argued that students can learn no more from this medium than they could learn emergency surgery from watching ER (Gyenes, 2004). However, to the contrary, many businesspeople, college professors, their students, and millions of other fans disagree (Jones \& Keveney, 2004).

Again, in a search of for any prior studies on The Apprentice, it has been exceedingly limited research. As with the case of Kinnick and Parton's (2005) study, there is still limited research conducted on The Apprentice. In addition, there is still no prior empirical research. As a basis for this research, this study attempts to fill that gap. This study will measure management and firing decisions of management students and compare their decisions to Trump's firing decisions. This study will be one of two studies conducted on The Apprentice. It will be the first to conducted empirical research on the show as well. 


\section{Hypotheses}

The purpose of the study is to determine if management students' firing decisions differed when compared to Donald Trumps' firing decisions on The Apprentice. The study used focus groups as a method of data collection. The students were administered a survey, which was used to collect observational data from the observations. Below are the proposed hypotheses for the study are:

- Hypothesis 1: Based on the episodes, with the boardroom firings, in The Apprentice, in many cases management students chose the project manager to be fired from the team.

- Hypothesis 2: In many cases, management students chose a team member to be fired from the team.

- Hypothesis 3: In many cases, management students agreed with Donald Trump’s firing decision in The Apprentice.

- Hypothesis 4: In many cases, management students disagreed with Donald Trump’s firing decision in The Apprentice.

The study used focus groups as a method of data collection. The primary objective of this research was to compare management students firing decisions to Trump’s firing decisions.

\section{Research Method}

\subsection{Research Design and Strategy}

This study used a non-experimental, exploratory research design. The study used a cross-sectional research design strategy, which attempted to collect quantifiable or quantitative data with two or more variables. This was conducted with management students as focus groups. This study used a survey research strategy. This study was conducted over a 2-year period with management students in the School of Business. There were 20 management classes that were shown prerecorded DVD episodes of The Apprentice. Different seasons were shown to the management students. Each of the students made his/her decisions concerning who should be fired.

\subsection{Survey Approach and Questionnaire}

The study was conducted using a survey approach. A 5-item questionnaire was used for the study. The procedures for conducting the study were: (a) participants were given the questionnaire at the beginning of the viewing; (b) the episode was shown for a duration of 60 minutes; (c) the episode was halted at the boardroom scenario when Trump selected the individual(s) to be fired; (d) participants were then instructed to fill out the questionnaire (Question 1) and make a decision regarding who should be fired (the project manager, team member, or both); (e) then the episode was resumed, with the board room scene, and the results of Trump's firing decision was shown; (f) after viewing Trump's firing decision, participants filled out Question 2, which asked if they agreed with the firing decision; (f) the questionnaires were collected; and (g) data were input into Statistical Package for Social Sciences (SPSS) version 20.0 for statistical analyses. 


\subsection{Sample and Data Collection}

There was a total sample of 173 participants. The data was collected from 20 different management classes over a two-year period. Demographic questions included gender, ethnicity, and three management questions. The age of the participants ranged from 18 to 57 years, with a mean age of 26 years. The participants were primarily undergraduate $(n=163)$ and graduate students $(n=10)$ in the School of Business. All students were management majors. Over a two-2 year period those participants viewed 20 different episodes of The Apprentice. The students' responses were measured and compared to Trump's firing decisions.

\section{Results of Study}

The study used management students as focus groups as a method of data collection. The population of interest consisted of management students in both undergraduate and graduate courses. Over the course of a two-year period the data was collected from two universities: public and private university in a large metropolitan city in Texas. Table 1 and 2 illustrate the demographic descriptive statistics. Table 1 illustrates the gender breakdown of the management students. The first column illustrates the frequency and the second column shows the percentage of the sample. Table 2 illustrates the student classification or undergraduate or graduate for the management course.

Table 1. Demographic results: gender of management students in study $(N=173)$

\begin{tabular}{lll}
\hline Gender & Frequency & \% of Sample \\
\hline Males & 78 & 45.1 \\
Female & 95 & 54.9 \\
\hline Total & 173 & 100.0 \\
\hline
\end{tabular}

Table 2. Demographic results: management student classification in study $(N=173)$

\begin{tabular}{lll}
\hline Student Classification Ranking & Frequency & \% of Sample \\
\hline Undergraduate & 163 & 94.2 \\
Graduate & 10 & 5.8 \\
\hline Total & 173 & 100.0 \\
\hline
\end{tabular}

Table 3 presents the demographic data on the ethnic breakdown of the management students. As indicated, $61.3 \%$ of the sample was represented Hispanic/Latino students. Notably, Asian students represented only $1.7 \%$ of the sample. 
Table 3. Demographic results: ethnicity of management students in study $(N=173)$

\begin{tabular}{lll}
\hline Ethnicity & Frequency & \% of Sample \\
\hline Asian (Pacific Islander) & 3 & 1.7 \\
Black (non-Hispanic) & 11 & 6.4 \\
Hispanic/Latino & 106 & 61.3 \\
White & 47 & 27.2 \\
Other & 6 & 3.5 \\
\hline Total & 173 & 100.0 \\
\hline
\end{tabular}

The study used measured the responses of management students' observations of The Apprentice episodes. Table 4 presents the responses of the Question 1 Who should be fired? In most of the case observations, $41.6 \%$ of the management students voted the project manager should be fired on the team. Of the lowest percentage of management students, $13.9 \%$ thought both the project manager and team member should be fired. Hypothesis 1 predicted that in many cases management students chose the project manager to be fired from the team. The results (41.6\%) of the statistics supported this hypothesis. Hypothesis 2 predicted that management students chose a team member to be fired from the team. The results of statistics did not support that (27.2\%).

Table 4. Study results of management students' opinion of Trump’s firing decision $(N=173)$

\begin{tabular}{lll}
\hline Question 1: Who Should Be Fired? & Frequency & \% of Sample \\
\hline Project Manager & 72 & 41.6 \\
Team Member & 47 & 27.2 \\
Neutral & 30 & 17.3 \\
Both Project Manager and Team Member & 24 & 13.9 \\
\hline Total & 173 & 100.0 \\
\hline
\end{tabular}

Table 5 shows the responses for Questions 2: Did you agree with Trump’s decision. There was some parity between the responses. The responses 1-Strongly Agree and 2-Agree were added together to test the hypothesis. Of the management students, $47.4 \%$ agreed with Trump's firing. However, 41.1\% disagreed with Trump's decision (again, 5-strongly disagree and 4-disagree were added together). The management students' responses were diverse in relation to Trump's decisions in The Apprentice. Hypothesis 3 predicted that in many cases, management students agreed with Donald Trump's firing decision in The Apprentice. The results (47.4\%) of the statistics supported this hypothesis. Hypothesis 4: In many cases, management students disagreed with Trump's firing decisions in The Apprentice. The results (41.1\%) of the statistics did not support this hypothesis. 
Table 5. Descriptive results of management students' opinion of Trump's firing decision $(N=173)$

\begin{tabular}{lll}
\hline Question 2: Did You Agree With Trump’s Decision? & Frequency & \% of Sample \\
\hline Strongly Agree & 38 & 22.0 \\
Agree & 44 & 25.4 \\
Neutral & 20 & 11.6 \\
Disagree & 29 & 16.8 \\
Strongly Disagree & 42 & 24.3 \\
\hline Total & 173 & 100.0 \\
\hline
\end{tabular}

\section{Inferential Statistics of the Data in the Study}

In order to determine how the two gender groups differ, a one-sample t-Test was used to group means. The management students were randomly divided into two groups. The experimental group was to be given questions in identifying their observations and responses of the firing decision. This analysis is used to determine which of the differences between group means are significant and which are not. The results of the test are summarized in Table 6. An examination of Question 1 indicates the female responses $(M=2.13, S D=1.044)$ had a greater mean, yet a lower standard deviation compared to the males $(M=1.92, S D=1.102)$. Question 2 indicates the female responses $(M=3.04, S D=1.529)$ had a greater mean and standard deviation compared to the males $(M=2.86, S D=1.492)$.

Table 6. Comparison between gender groups of management students $(N=173)$

\begin{tabular}{llrr}
\hline “The Apprentice” Questions & Gender & \multicolumn{2}{l}{$S$} \\
\hline Q1: Who should be fired? & Males & 1.92 & 1.102 \\
& Females & 2.13 & 1.044 \\
\hline Q2: Did you agree with Trump’s firing decision? & Males & 2.86 & 1.492 \\
& Females & 3.04 & 1.529 \\
\hline
\end{tabular}

An independent sample t-Test was used in order to assess the differences by gender. The results of the test are summarized in Table 7. An examination of Question 1 shows the responses by gender. The results of the t-test revealed there were no significant differences between gender of management students' responses $(F=.460, p=.499)(t=-1.242 ; d f=171)$. An examination of Question 2 shows the responses by gender. The results of the t-test revealed there was no significant differences based on gender $(F=.244, p=.622)(t=-792 ; d f=171)$. The results of the t-test indicated there were no significant differences based on gender. 
Table 7. Independent sample t-Test of gender of the management students $(N=173)$

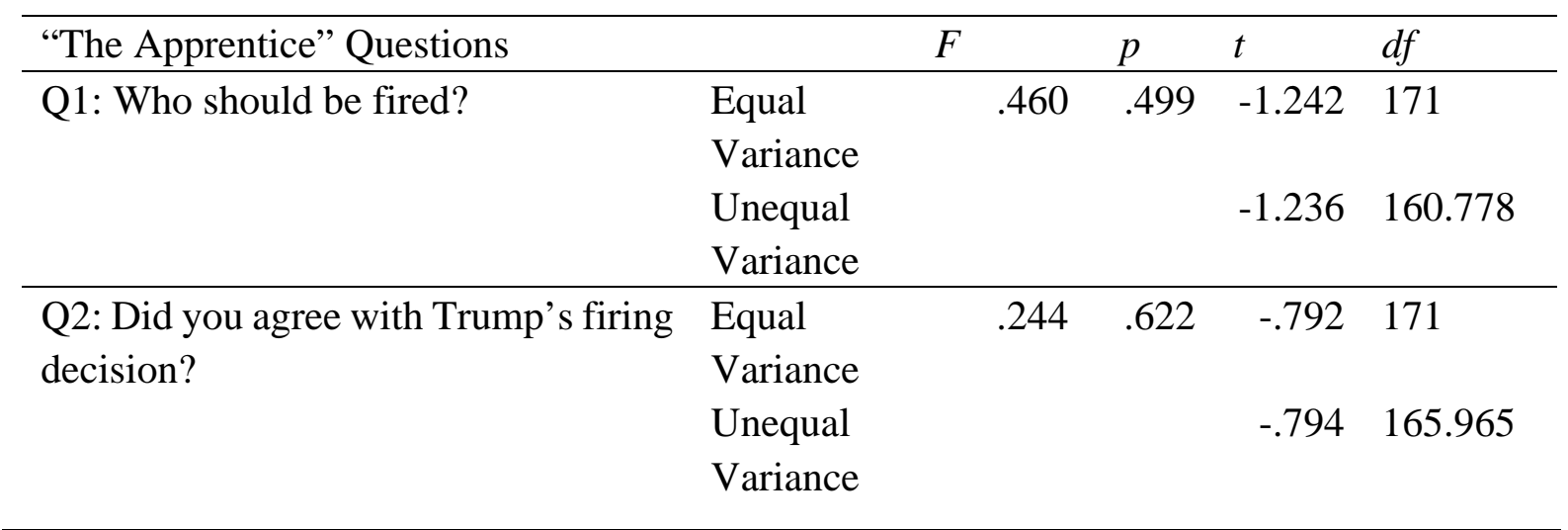

*Notice: $p<.005$

An ANOVA was used In order to assess the differences between ethnic groups. The ANOVA indicated no significant differences in responses of the management students to the Question 1 and Question 2. The results of the test are summarized in Table 8. An examination of Question 1 shows the ethnic group responses. The results of the ANOVA revealed there was no significant differences between ethnic groups of management students' responses ( $S S=5.197$, $M S=1.299)(F=1.13 ; p=.343)$. An examination of Question 2 shows the ethnic group responses. The results of the ANOVA revealed there was no significant differences between ethnic groups of management students' responses $(S S=8.791, M S=2.198)(F=.962 ; p=.430)$. The results of the ANOVA indicated there were no significant differences between the ethnic groups.

Table 8. ANOVA results with ethnic groups of management students $(N=173)$

\begin{tabular}{lrrrr}
\hline “The Apprentice” Questions & \multicolumn{1}{c}{ SS } & MS & \multicolumn{1}{c}{ F } & \multicolumn{1}{c}{$p$} \\
\hline Q1: Who should be fired? & & & & \\
Between Groups & 5.197 & 1.299 & 1.133 & .343 \\
Within Groups & 192.595 & 1.146 & & \\
\hline Q2: Did you agree with Trump’s firing decision? & & & & \\
Between Groups & 8.791 & 2.198 & .962 & .430 \\
Within Groups & 383.926 & 2.285 & & \\
\hline
\end{tabular}

*Notice: $p<.005$

Table 9 shows the results of the Pearson correlation between Question 1 and Question 2. Based on the results, there is no correlation between the responses to the questions from The Apprentice study. The correlation coefficients indicate there is no relationship between the two questions. There is no direct relationship between the variables. The results also indicate there is no causal relationship between the questions as well. 
Table 9. Correlation between survey questions (Q1 and Q2) with The Apprentice study

“The Apprentice” Questions $\quad(N=173) \quad(N=173)$

\begin{tabular}{lll}
\hline & $\begin{array}{l}\text { Q1: Who should } \\
\text { be fired? }\end{array}$ & $\begin{array}{l}\text { Q2: Did you } \\
\text { agree } \\
\text { Trump's firing } \\
\text { decision? }\end{array}$ \\
\hline Q1: Who should be fired? & 1.00 & -.125 \\
Q2: Did you agree with Trump's firing decision? & -.1 .25 & 1.00 \\
\hline Sig. (2-tailed) & .102 & .102 \\
Sum of Squares and Cross products & -34.757 & -34.757 \\
& 197.792 & 392.717 \\
\hline Covariance & -202 & -.202 \\
& 1.150 & 2.283 \\
\hline
\end{tabular}

\section{Discussion}

There was a total sample of 173 participants from 20 different business management classes for this study. This study took place over a two-year period. Demographic questions included gender, ethnicity, and three management questions. There were six ethnic groups that participated in this study. The age of the participants ranged from 18 to 57 years of age. The participants were primarily undergraduates $(n=163)$ and graduates $(n=10)$ in School of Business. All of the students were management students. Considering the mean age of the participants was 26, a considerable number of the students were over 25 years of age. There were 78 males and 95 females. Over a two-2 year period those participants viewed 15 different episodes of The Apprentice with Donald Trump. The students were responses were measured and compared to Trump’s firing decisions.

The study used four types of statistical analyses. First the results of the analysis compared the participants by gender. This analysis was used to determine which of the differences between males and females were significant. The results of one sample t-Test indicated there was no significant difference between management students based on gender. It was determine there was no relationship between gender and means and standard deviations. Another analysis was conducted on gender. An independent sample t-Test was conducted. This was done to further exam if gender was a significant influence. The results of the one sample t-Test indicated there was no significant difference between management students based on gender. Again, the results of analysis indicated that gender was not a factor in the data. One possible explanation for this was that male and female management students frame their thinking along the same line therefore gender cannot be a factor in their decision making.

The second analysis was conducted on the ethnic groups to see if there were if differences. The objective was to examine the participants by ethnic groups. An ANOVA was used In 
order to assess the differences between ethnic groups. The results indicated there was no significant difference between management students based on ethnicity. Again, a possible explanation for this was that decisions from the management students followed a similar framework of thinking. This was a contributing factor that could not be measured along ethnic lines.

The last analysis, a Pearson correlation was conducted. The objective was to see if there were any correlations between Question 1 and Question 2. Based on the results of the correlation analysis, there was not a correlation between the questions. The possible rationale behind the results was because of the procedure used to collect the responses. As discussed in the earlier section of the article, those questions were answered prior to seeing Trump's firing decision. This may have affected the results. As a result, the correlation could not be established. Another rationale was there was no causal relationship between the questions. So the results of the analysis were not surprising.

The results of this study indicate that gender and ethnicity were no factors in the data collected from the management students. Also the results of the study answered the hypothesis questions. For Hypothesis 1, the management students chose the project manager to be fired from the team. Based on the results, the Hypothesis 1 was confirmed. For Hypothesis 2, management students chose a team member to be fired from the team. Based on the results, the Hypothesis 2 was not confirmed. For Hypothesis 3, management students agreed with Donald Trump's firing decision in The Apprentice. The results of the study did not support Hypothesis 3. Lastly, for Hypothesis 4, management students agreed with Donald Trump's firing decision in The Apprentice. Based on the results of the study, Hypothesis 3 was supported. The results can be useful to field of management theorists and most particularly to practioners in the industry.

\section{Limitations of the Study}

This study intended to examine if management students' termination decisions compared to Donald Trump's decision after reviewing various episodes of The Apprentice. There were some limitations in this study. The first limitation involved recruiting research participants. There was a limited number of available participants. The sampling frame of the university was a limitation. Due to time constraints of the participants this caused a shortage of available participants. Another limitation was the use of a convenience sample of participants, who were recruited from the university. It would have been impossible to conduct a random sample for an observation study. The researcher had to use university management students as the sampling frame. This was a limitation because the results may not be applicable beyond the sample of the study. A last limitation was the lack of diversity with the sample. All of students were management students from the School of Business. This had a tendency of causing the sample to be one-dimensional. Given the purpose of the study, this study could have been expanded to non-management students. It would be useful to replicate the research using a more diverse sample frame with both business and non-business students.

\section{Recommendations for Future Research}

There are many opportunities recommendations that can further expand the scope of this study. First, one recommendation would be the inclusion of non-business majors from other fields 
of study such as psychology, sociology, education and maybe sciences. A diverse sample of participants would provide a much richer sample and could expand beyond the limitations of this study. They could provide an interesting perspective on reviewing The Apprentice and firing decisions.

A second recommendation would be to expand the questionnaire of the instrument that was used for the study. Considering the fact the instrument was very limited, it would be an opportunity to collect more demographic data such as age, field of study and other descriptive. This would provide researchers further analyses. The lack of collecting data for this study and other descriptive data was a missed opportunity. A future study of this type could perhaps expand beyond the limitations of this study. Additionally, estimating the age range of the sample, a wider distribution of ages could provide some interesting results. Lastly, another future consideration for replication of this study would be to collect data on management practioners in the industry. A future study of this type would not only provide some groundbreaking research but would provide an interesting insight on management practioner's insights on firing decisions. That would be an interesting study.

\section{Conclusions and Critical Observations}

The purpose of this study was to conduct empirical research on Donald Trump's The Apprentice with management students. The researcher found a gap in the prior research on The Apprentice used in examining management and business behavior. The study extended beyond the prior studies by conducting empirical research on management decisions on termination. A 5-item instrument was used to measure the opinions of management students. The data were collected from the participants. Descriptive statistics were used to measure management decisions of the management students. The participants of the study were both male and female. The majority of the participants were management students from the School of Business.

There were four statistical analyses conducted on the data. An independent sample t-Test, ANOVA, and a Pearson correlation were conducted on the data. The statistical analyses were conducted on the two questions in the instrument: (a) Question 1 - Who Should Be Fired; and (b) Question 2 - Did You Agree with Trump's Decision? Results of the correlation analysis indicated a statistically significant negative correlation for Question 1 and Question 2. There were no statistically significant findings for the correlation between the two variables.

The independent sample t-Test was conducted on gender (male and female) differences with management students. The purpose was to measure if there were any significant differences based on gender. The results of the independent t-Test indicated there were on slight differences between the gender groups. There were no statistical significances between gender groups. An ANOVA was conducted on the ethnic groups in sample with the management students. There were six minority groups in the sample (Asian, Black (non-Hispanic), Hispanic/Latino, White and Other). Results of the ANOVA indicated there were no significant differences between ethnic groups in terms of Question 1 and Questions 2. The ethnic groups of management students indicated no statistical significance. 


\section{Macrothink Institute ${ }^{\mathrm{TM}}$}

The main implication here is that management students did not differ in their firing decisions compared to Donald Trump's on The Apprentice. Based on the results of the descriptive statistics, $47.4 \%$ of management students' firing decisions agreed with Trump's decisions on The Apprentice. Only 41.1\% disagreed with Trump's firing decisions. This indicates that management students are astute at making sound firing decisions.

The conclusions of the research suggest that based on viewing episodes of The Apprentice: (a) there was no significance based on gender between management students; (b) there was no significance based on ethnicity between management students; and (c) there were no correlation between whom the students thought should be fired and Donald Trump's firing decisions. The researcher concludes from the study despite gender and ethnicity of management students; they proved to be astute at making termination decisions. The findings were rather surprising considering the theoretical foundation of management principles that could have an influence on management students.

\section{References}

Henle, C. (2005). Bad apples or bad barrels? A former CEO discusses the interplay of person and situation with implications for business education. Academy of management learning \& education, 6(3), 346-355.

Kinnick, K. \& Parton, S. (2005). Workplace communication: What the Apprentices teaches about communication skills, Business communication quarterly, 68(4), 429-456. http://dx.doi.org/10.1177/1080569905282099

Popejoy, B. (2004). A question of leadership, Leadership in action, 24(4), 13. http://dx.doi.org/10.1002/lia.1077

Elliot, M. (March 2004). Review: There’s no business like show business. Industrial engineer, 2(4), 39.

Ho, R. (2004, March 3). Professor Trump. The Atlanta journal-constitution, pp. E1, E4.

Herrera, I. D. (2004, April 5). “The Apprentice” exposes the reality of glass ceiling. USA today, p. 13A. Retrieved on August 5, 2012 from http://www.usatoday.com/news/opinion/editorials/2004-04-04-herrera_x.htm

Gyenes, K. (2004, April 15). Apprentice” sparks classroom discussions. Retrieved August 5, 2012, $\quad$ from http://articles.cnn.com/2004-04-15/entertainment/apprentice.biz.schools_1_jones-reality-sho w-donald-trump?_s=PM:SHOWBIZ

Jones, D., \& Keveney, B. (2004, April 15). 10 lessons of “The Apprentice.” USA today, p. 1A.

Retrieved August 5, 2004, from http://www.usatoday.com/money/media/2004-04-15-apprentice-lessons_x.htm 